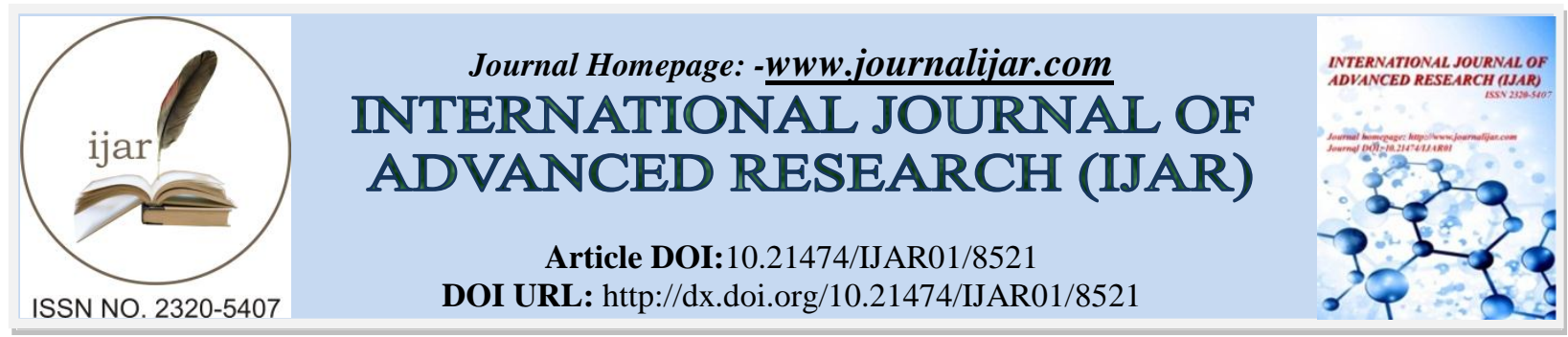

RESEARCH ARTICLE

\title{
HEMODIALYSIS ACCESS PROCEDURES IN PEDIATRIC PATIENTS WITH END STAGE RENAL DISEASE- OUTCOME ANALYSIS.
}

Balakumar and M. Bakthavatchalam.

\section{Manuscript Info}

\section{Manuscript History}

Received: 06 December 2018

Final Accepted: 08 January 2019

Published: February 2019

Key words:-

HD catheter, av fistula, primary patency.
Abstract

Background: Arteriovenous fistulae (AVF) are the dialysis access modality of choice for patients with end stage renal disease (ESRD). Many children have poor vein caliber which renders them unsuitable for performing AV fistula and those end up in chronic tunneled hemodialysis catheter. The longer maturation time in children than that in adults and the technical difficulties imposed by small diameters of the vessels are other challenges in operation on pediatric patients.

Methods: Data collected from pediatric patients with endstage renal failure in whom HD access procedure was performed retrospectively and followed up and the following data were analyzed. study performed in Govt Omandurar Multi Super Speciality Hospital,Chennai. Affiliated to, The Tamilnadu Dr.M.G.R Medical University. Etiology of renal failure, time on dialysis, CKD history, and transplantation and type of HD access procedure, patency and functioning at 6 months for both were recorded. Patients of age 0 to 15 were included in this study, age was the only inclusion criteria.

Results: children with growth less than 50th percentile tend to have poor vein caliber with ending in chronic HD catheter. Pre operative and prior vene puncture was present in $(80 \%)$ patients in whom further AV fistula was not feasible. Patients with renal failure secondary to obstructive uropathy were favoring creation of AV fistula. Patients with no prior history of ICU admission for volume over load had better feasibility of AVF creation. Average time of $\mathrm{HD}$ ( Hemo Dialysis) catheter patency in 6 months was $92 \%$. Primary patency of AV fistula was $85 \%$ in 6 months. Maturation rates and secondary failure was not evaluated in this study.

Conclusion: anatomic factors like vein diameter, prior venepuncture highly influence the type of HD access procedure. at 6 months chronic tunneled catheter had better patency than AV fistula. Proper education of the medical fraternity dealing with pediatric renal failure patients regarding these factor will help in long term functioning of the fistulas and patency of the HD catheter and survival. 


\section{Introduction:-}

Arteriovenous fistulae (AVF) are the dialysis access modality of choice for patients with end stage renal disease (ESRD) [1,2]. They are associated with a six-fold reduction in the risk of systemic sepsis [3] and lower all cause and cardiovascular mortality than tunneled central venous catheters (TCVCs) [4,5]. For this reason both the UK Renal Association and the Fistula First Initiative in the United States have set targets that two-thirds of incident haemodialysis (HD) patients should commence dialysis via an AVF $[5,6]$.

\section{Methods:-}

Data collected retrospectively and followed up and the following data were analyzed. Etiology of renal failure, time on dialysis, CVC history, and transplantation and type of HD access procedure, patency and functioning at 6 months for both were recorded. Patients of age 0 to 15 were included in this study, age was the only inclusion criteria.

Etiology of renal failure was identified for each patient and then divided into one of five general categories: structural, glomerulonephritis, nephrotic syndrome, metabolic, and other. The creation of each fistula was performed by one of two surgeons, and the type of access created was surgeon-dependent. Vein mapping was performed on all patients and evaluated by each surgeon for suitability of vein size, and in general, the minimum size cutoff was 2.0 $\mathrm{mm}$ for forearm veins and $2.5 \mathrm{~mm}$ for upper arm veins.. All AVFs were performed with a standard end-to-side anastamosis with a continuous running monofilament suture. To decrease the vasospastic response from arterial clamping and vessel dissection, tourniquet occlusion was used for inflow control in selected cases. Loupe magnification was used in all surgical cases. An operating microscope was used by one of the two surgeons on a case-by-case basis as determined by artery size. Patients were seen routinely at 2 and 6 weeks postoperatively for an initial wound check and clearance for use of the fistula

For chronic tunneled hemodialysis catheter procedure, vein mapping was done to assess the feasibility of AV access and those patients who were not suitable for AV fistula were selected for catheter insertion. Surgery was performed under general anesthesia. And image intensifier was used to confirm the position and perform a fogram if necessary and aiding in positioning of the access wire. Hemodialysis was initiated on the same day of the procedure.

\section{Results:-}

The mean age of the patients in our study was $10.4 \mathrm{y}$. Male and female were equal in number, totally 35 patients who underwent AV fistula were studied and included in the study. They were evaluated for patency in the 2nd and 6th week by physical examination. all the patient underwent brachiocephalic fistula with 3 patients undergoing brachiobasilic with primary transposition. There were $3 \mathrm{AV}$ fistula failure within 2 weeks and 2 within 6 months. Failure rate of AV fistula at 6 months interval was 15\%. 12 patients had HD catheter insertion and at the end of 6 months and 1 patient had catheter occlusion necessitating removal. Patency rate at 6 months interval remained at $92 \%$.

\section{Factors favoring AV access procedures were}

1. patients in whom HD not yet initialized, and with stable CKD. (15\%)

2. 2.absence of prior ICU admission for volume overload. (40\%)

3. CKD secondary to obstructive uropathy $(20 \%)$

4. age $>8$ years. $(25 \%)$

\section{Factors favoring HD catheter insertion.}

1. clinically unstable patients with recurrent episodes of volume overload (5\%)

2. associated cardiac pathology $(5 \%)$

3. multiple ICU admission for volume overload (15\%)

4. secondary CKD following systemic illness. (20\%)

5. patients with previous multiple access failure $(50 \%)$

infection rates in both group remained negligible with aseptic measures during procedure. hygienic practices in maintaining the HD catheter, directly influence the longevity of the catheter patency.

At the end of 6 months, HD catheter had better functioning capacity than AV fistula access, 


\section{Discussion:-}

The primary patency rates in pediatric populations at 6 months to 2 years have been reported to be as approximately $50 \%-65 \%$, which is similar to the results in adults [6,10-12]. A few recent studies are available showing the excellent outcomes in children [13]. Wartman et al. evaluated the outcomes of 101 AVFs and demonstrated primary and secondary patency rates at 2 years as $83 \%$ and $92 \%$, respectively (14).

Although these documented outcomes are acceptable, some have considered the incidence of primary failure to be sufficiently high to be a barrier for AVF placement in children and adolescents. The longer maturation time in children than that in adults and the technical difficulties imposed by small diameters of the vessels are other reasons for a reluctance to create AVFs in children [11].

Based on such factors, CVCs have remained as the most commonly used access in children on chronic HD . As is With the success of Fistula First Breakthrough Initiative, the prevalence of native AVF was on the rise and the general perception with regard to AVFs had changed (14).

This study showed an acceptable incidence of primary failure. By undertaking careful preoperative evaluation and providing postoperative care, the risk of primary failure can be lowered. proper vein selection is required especially in small children. The patency rates achieved in this study were comparable to those in adult patients [17]. Thus, placement of AVFs in children and adolescents should be actively considered when a permanent vascular access for long-term HD is required.

Even though endovascular or surgical treatment was required to achieve maturation and early patency, mid- and long-term patency were maintained without the need for frequent interventions. During the first year after AVF creation, active surveillance and timely intervention are important to achieve a favorable outcome.

AVF creation should be considered primarily even in patients with plans for transplantation if a living donor is not available.

Weak arterial inflow and small vein diameter are inevitable in children. Several methods, such as the use of microsurgical techniques, have been attempted to overcome these difficulties and increase patency in small children. Bagolan et al. [10] reported that adoption of microsurgical techniques significantly lowered the primary failure rate. Even though we achieved comparable results to that study without using a microscope, we think microsurgical techniques are worth adopting in some subgroups of patients, such as those with low body weight [10,19,20].

Antiplatelet medications and cessation of anti-hypertensive medications were other methods recommended [16]. However, there are few evidences supporting the routine use of antithrombotic therapy. Preoperative duplex is one of the preferred methods to improve AVF maturation rates and highly recommended these days. It may improve outcomes of AVF, although not mandatory [21]. Further study with duplex results is needed to prove the importance of preoperative vein mapping in pediatric patients.

Many patients with failed AVFs were non-compliant to instructions and precautions due to age or mental retardation accompanying the original disease. During the early postoperative period, especially in a pediatric population, close supervision is required so as to not compress the AVF site by bending the arm for a long time. To achieve successful postoperative care and patient education levels, a multidisciplinary team that includes vascular surgeons, nephrologists, and HD nurses is important [15].

\section{Limitations:-}

Small study sample. Lack of statistical analysis. No long term follow up, absence of hypercoagulable work up. Were the limitations in this study.

\section{Conclusion:-}

Creation of AVF for HD in children has peculiar challenges different from adult AV fistulas. while anatomic factors like vein diameter, prior venepuncture, highly influence the type of access procedure possible. general condition of the patient and associated comorbities highly influence the favorable type of HD access. maintaining asepsis during 
the procedure and during hemodialysis helps in maintainingb the patencyof the hemodialysis catheter. proper education of the medical fraternity dealing with pediatric renal failure patients regarding these factor will help in long term functioning of the fistulas and HD catheter patency..

\section{References:-}

1. Fogarty D, Cullen R: UK Renal Registry 16th Annual Report. Renal Association [Acceesed online on 12th November 2014: https://www.renalreg. org/wp-content/uploads/2014/09/00a-Introduction.pdf]

2. National Kidney Foundation: KDOQI clinical practice guidelines and clinical practice recommendations for 2006 updates: haemodialysisadequacy, peritoneal dialysis adequacy and vascular access. Am J Kidney Dis 2010, 56:566-577.

3. Thomson PC, Stirling CM, Geddes CC, Morris ST, Mactier RA: Vascular access in haemodialysis patients: a modifiable risk factor for bacteraemia and death. QJM 2007, 100(7):415-422.

4. Bray BD, Boyd J, Daly C, Donaldson K, Doyle A, Fox JG, Innes A, Khan I, Peel RK, Severn A, Shilliday I, Simpson K, Stewart GA, Traynor J, Metcalfe W: Vascular access type and risk of mortality in a national prospective cohort of haemodialysis patients. QJM 2012, 105(11):1097.

5. Fluck R, Kumwenda M: Clinical Practice Guidelines: Vascular Access for Haemodialysis, The Renal Association 5th ed. 2011.

6. Ramage IJ, Bailie A, Tyerman KS, McColl JH, Pollard SG, Fitzpatrick MM. Vascular access sur vival in children and young adults receiving long-term hemodialysis. Am J Kidney Dis 2005;45:708-714.

7. Fadrowski JJ, Hwang W, Neu AM, Fivush BA, Furth SL. Patterns of use of vascular catheters for hemodialysis in children in the United States. Am J Kidney Dis 2009;53:91-98.

8. Hayes WN, Watson AR, Callaghan N, Wright E, Stefanidis CJ; European Pediatric Dialysis Working Group. Vascular access: choice and complications in European paediatric haemodialysis units. Pediatr Nephrol 2012; 27:999-1004.

9. Sidawy AN, Gray R, Besarab A, Henry M, Ascher E, Silva M Jr, et al. Recommended standards for reports dealing with arteriovenous hemodialysis accesses. J Vasc Surg 2002;35: 603-610.

10. Bagolan P, Spagnoli A, Ciprandi G, Picca S, Leozappa G, Nahom A, et al. A ten-year experience of BresciaCimino arteriovenous $\mathrm{f}$ istula in children: technical evolution and refinements. J Vasc Surg 1998;27:640-644.

11. Briones L, Diaz Moreno A, Sierre S, Lopez L, Lipsich J, Adragna M. Permanent vascular access survival in children on long-term chronic hemodialysis. Pediatr Nephrol 2010;25:1731- 1738.

12. Sheth RD, Brandt ML, Brewer ED, Nuchtern JG, Kale AS, Goldstein SL. Permanent hemodialysis vascular access survival in children and adolescents with end-stage renal disease. Kidney Int 2002;62:1864-1869.

13. Gradman WS, Lerner G, Mentser M, Rodriguez H, Kamil ES. Experience with autogenous arteriovenous access for hemodialysis in children and adolescents. Ann Vasc Surg 2005;19:609- 612.

14. War tman SM, Rosen D, Woo K, Gradman WS, Weaver FA, Rowe V. Outcomes with arteriovenous fistulas in a pediatric population. J Vasc Surg 2014;60:170-174.

15. Chand DH, Bednarz D, Eagleton M, Krajewski L. A vascular access team can increase AV fistula creation in pediatric ESRD patients: a single center experience. Semin Dial 2009; 22:679-683.

16. Manook M, Calder F. Practical aspects of arteriovenous fistula formation in the pediatric population. Pediatr Nephrol 2013;28:885-893.

17. Son HJ, Min SK, Min SI, Park YJ, Ha J, Kim SJ. Evaluation of the efficacy of the forearm basilic vein transposition arteriovenous fistula. J Vasc Surg 2010;51:667-672.

18. Korean Network for Organ Sharing (KONOS). 2014 KONOS Annual Report [Internet]. Seoul: KONOS; 2015 [cited 2015 Sep 15]. Availabe from: https:// www.konos.go.kr.

19. Bourquelot P, Cussenot O, Corbi P, Pillion G, Gagnadoux MF, Bensman A, et al. Microsurgical creation and follow-up of arteriovenous fistulae for chronic haemodialysis in children. Pediatr Nephrol 1990;4:156-159.

20. Sanabia J, Polo JR, Morales MD, Canals MJ, Polo J, Serantes A. Microsurgery in gaining paediatric vascular access for haemodialysis. Microsurgery 1993;14:276-279.

21. Wong CS, McNicholas N, Healy D, Clarke-Moloney M, Coffey JC, Grace PA, et al. A systematic review of preoperative duplex ultrasonography and arteriovenous fistula formation. J Vasc Surg 2013;57:1129-1133. 